\title{
81. Xanthophores on the Surface of the Midgut and the Hindgut of the Freshwater Shrimp, Caridina denticulata
}

\author{
By Takanori Tsuruda and Mitsuharu MiYawaki \\ Department of Biology, Faculty of Science, \\ Kumamoto University, Kumamoto 860 \\ (Communicated by Sajiro Makino, M. J. A., Sept. 12, 1985)
}

The occurrence of chromatophores on internal organs, such as intestine, ventral nerve cord and ovary, of decapod crustaceans (Natantia) has been reported previously (Robison and Charlton, 1973; Lambert and Fingerman, 1978; McNamara, 1979, 1980; Miyawaki and Taketomi, 1984; Miyawaki and Tsuruda, $1984,1985 \mathrm{a}, \mathrm{b})$. Some of these authors not only have dealt with the occurrence and structure of these chromatophores but also with the humoral control of the pigment movement in these cells. In our laboratory the chromatophores on the midgut, hindgut and ventral nerve cord of a freshwater shrimp, Caridina denticulata, have been studied recently. Erythrophores and leucophores were located on these organs, the migration of the pigment granules in both types of chromatophores was found to be under the control of eyestalk hormones (Miyawaki and Tsuruda, 1984, 1985b). This paper deals with the occurrence of yellow chromatophores, xanthophores, which until recently had not been observed so far on these internal organs.

Material and methods. The freshwater shrimp, Caridina denticulata, were ccllected from the Lake Edzu in Kumamoto City throughout the year. Some of the shrimp were dissected just after collection, others were used after rearing in the laboratory aquaria. The water temperature was maintained at about $25^{\circ} \mathrm{C}$, and illumination at $160 \mathrm{Lux}$ was on a $12 \mathrm{~L}: 12 \mathrm{D}$ cycle.

The mid- and hindgut of the shrimp were dissected out and mounted on a glass slide with or without a cover slip, according to the design of the experiment. The isolated organs were observed by means of a slight microscope. The routine electron microscopic observation of tissues fixed in $4 \%$ glutaraldehyde, postfixed in $1 \%$ osmium tetroxide, and embedded in araldite resins, was also carried out. Thin sections were stained with uranyl acetate only or stained additionally with lead citrate. In addition, the yellow pigment-containing branches of chromatophores were isolated microsurgically and observed under the electron microscopy.

Results. Our observations with the light microscope suggested that some part of chromatophores contained both red and yellow pigment granules. This possibility was raised because only after the red pigment had become concentrated in the center of the cell was the cell processes filled with yellow pigment as seen in Fig. 1. We had at first thought that these yellow processes simply represented processes devoid of pigment granules after the concentration of the red pigment had occurred. On the basis of the electron microscopic observations it appeared at first that there might be two types of red chromatophores, one was with ordinary large electron dense granules and the other with much smaller and lighter ones (Miyawaki and Tsuruda, 1984). But when we observed micro- 


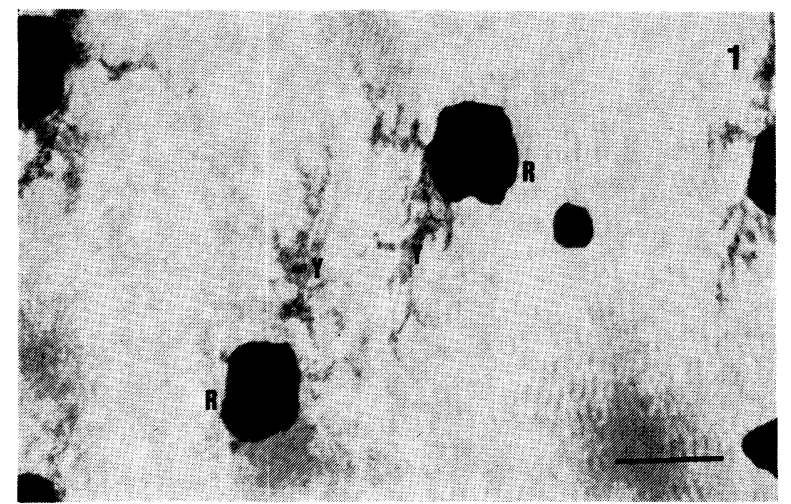

Fig. 1. Light micrograph of chromatophores on the surface of hindgut tissue of Caridina denticulata showing erythrophore (R) and xanthophore (Y) with dispersed pigment. Scale bar $=50 \mu \mathrm{m}$.

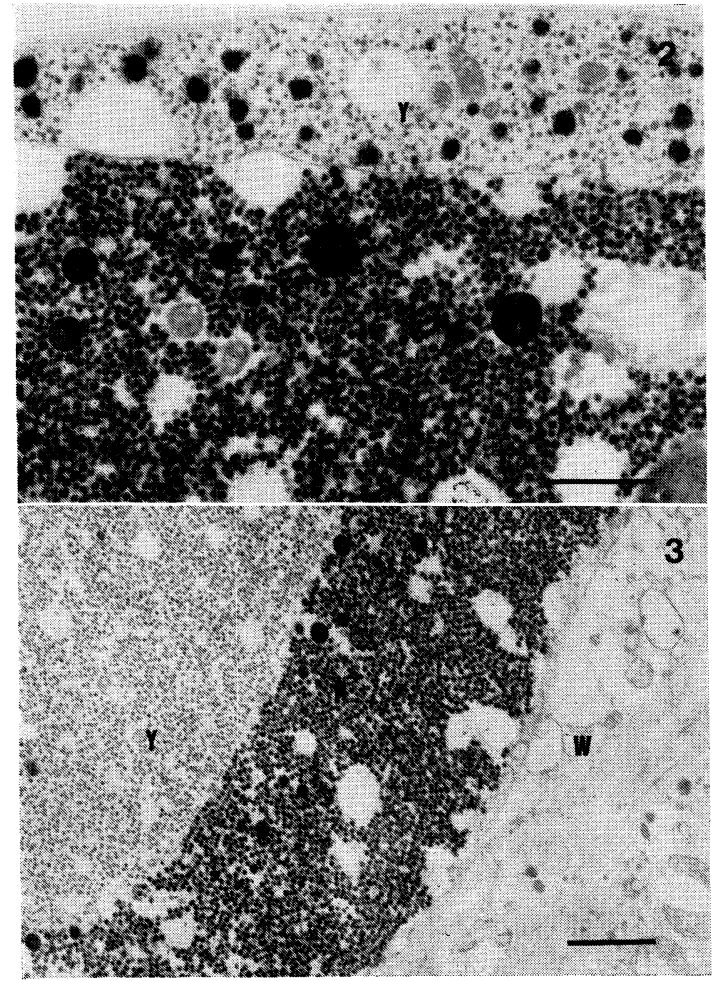

Figs. 2-3. 2: Electron micrograph of pigment granules in midgut chromatophores; yellow (Y) and red (R) granules are shown. Scale $=2 \mu \mathrm{m}$. 3: Electron micrograph of the three types of chromatophores in the integument; yellow (Y), red (R) and white (W) pigment granules are shown. Scale $=2 \mu \mathrm{m}$. 
surgically isolated yellow parts of erythrophores with the electron microscope a different interpretation came to light. The results of this procedure showed that these yellow processes were filled with the small pigment granules, and did not represent the second different type of erythrophore nor the empty room of the erythrophore (Fig. 2). These yellow cells were filled with small granules. The distinct cell membranes could be seen between the aggregations of ordinary red pigment granules and the smaller granules, which strongly suggests (if not actually proving) that these two kinds of granules are in different cells, i.e., the smaller granules being in xanthophores. The integumentary xanthophores contained also the same type small pigment granule (Fig. 3). This fact seems to provide further evidence for that the yellow processes of the erythrophores on the intestine and the ventral nerve cord belong to xanthophore, and that there is not present two kinds of erythrophores.

Discussion. In a previous paper, Miyawaki and Tsuruda (1984) suggested that two kinds of red chromatophores on the midgut and ventral nerve cord of the present species, one with large pigment granules and the other with small pigment granules. However, the results of the present study showed that the small granules are not the red pigment granules but the granules of xanthophores. So the previous interpretation should be revised. The erythrophores and the xanthophores are in intimate contact, and the leucophores are usually in close contact with both cell types also. These facts suggest that a cluster of the three types chromatophores is embryologically derived from a single cell.

Elofsson and Kauri (1971) described the ultrastructure of the integumentary chromatophores of Crangon and Pandalus. The white pigment granules of Crangon and Pandalus are almost identical to those of Caridina denticulata. But the ultrastructure of the red and yellow pigment in Crangon and Pandalus is quite different from those of $C$. denticulata. The reason for the differences is not clear at the present time. Species difference or the difference in the methods of the isolation and fixation of the chromatophores are likely possible explanation.

In the previous papers (Miyawaki and Taketomi, 1984; Miyawaki and Tsuruda, 1984, 1985a, b), we had reported that the concentration and dispersion of the pigment granules in the erythrophores and leucophores were influenced not only by removal of the eyestalks, but also by the administration of the extracts of the eyestalks. However, we have not yet determined whether these xanthophores are also controlled by an eyestalk hormone.

Acknowledgements. We express cordial thanks to Professor Milton Fingerman, Tulane University, New Orleans, Louisiana, for his critical reading of this manuscript. The authors are also indebted to Dr. Sajiro Makino, M. J. A., Professor Emeritus of the Hokkaido University for his review of the manuscript.

\section{References}

Elofsson, R., and Kauri, T. (1971) : J. Ultrastructure Res., 36, 263-270.

Lambert, D. T., and Fingerman, M. (1978) : Biol. Bull., 155, 563-575.

McNamara, J. C. (1979) : J. Exp. Mar. Biol. Ecol., 40, 193-199.

(1980): ibid., 46, 219-229.

Miyawaki, M., and Taketomi, Y. (1984) : Proc. Japan. Acad., 60B, 13-16.

Miyawaki, M., and Tsuruda, T. (1984) : ibid., 60B, 241-244.

(1985a) : ibid., 61B, 16-19.

- $(1985 \mathrm{~b})$ : ibid., 61B, 161-164.

Robison, W. G. Jr., and Charlton, J. S. (1973) : J. Exp. Zool., 186, 279-304. 